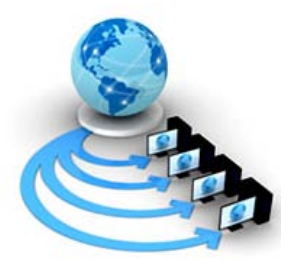

Volume 9, No. 2, March-April 2018

ISSN No. 0976-5697

International Journal of Advanced Research in Computer Science

RESEARCH PAPER

\author{
Available Online at www.ijarcs.info
}

\title{
BIG DATA TECHNOLOGIES FOR E-BUSINESS- FUTURE OPPORTUNITIES, CHALLENGES AHEAD AND GROWING TRENDS
}

\author{
Avinash B.M. \\ Assistant Professor \\ Ramaiah Institute of Management \\ Bangalore, India
}

\author{
Dr.S.Harish Babu \\ HOD, Department of Management Studies \\ Nitte Meenakshi Institute of Technology, Yelahanka, \\ Bangalore, India
}

\begin{abstract}
E-Business today is considered as one of the most important and popular trends in business. E-Commerce, which is limited to online transactions i.e. buying and selling goods/services over the internet, has a line of difference with E-Business that, in addition, covers all Internetbased communication and interactions with suppliers, manufacturers, logistics, and customers with the aim of improving business efficiency and process. To gain a competitive edge over the peers in relation to costs, revenues and customer base, companies bring in robust technologies that can create a formidable platform to achieve greater performance. One such breakthrough technology largely used is Big Data Analytics that can handle Volume, Velocity, Variety, and Veracity of data that is generated in the real time. This research paper focuses on understanding the need for Big Data Analytics in E-Business companies, what opportunities can be harnessed by the use of it and the challenges that need to be addressed.
\end{abstract}

Keywords: Big Data Analytics, Big data for E-Business, Analytics for E-Business, Big Data opportunities, Big Data Challenges

\section{INTRODUCTION}

A. Big Data: "I don't think anybody really talks about small data any more... anything which is data is now big data." Dr. Boris Mouzykantskii, IPONWEB.

In the current business scenario, data is getting rapidly generated and is considered as an asset that creates value. To extract meaningful value from such data, there is a need for technologies and built-in architectures.[1]

Performing effective analysis using traditional means and handling a large amount of data that is growing at a great speed is a challenge.[2]

To address this, we examine how Big Data technology brings benefits that help in harnessing opportunities and the challenges it poses.[1]

The term Big Data is referred to data that are voluminous in size and surpasses the handling capability of traditional database systems. The data is so enormous and are created so quickly that it does not fit into traditional databases. [2]

\section{Big Data Market is Predicted to be Worth $\$ 46.34$ Billion by 2018}

Fig. 1. Big Data market is predicted to be worth $\$ 46.34$ billion by 2018

(Source: www.easylearning.guru)

Gartner, Inc. defined Big Data as "Big Data is high volume, high velocity, and high variety information assets that

demand cost-effective, innovative way of processing information for better insights and decision making”.[3]

Dr.Phil Mui of Acxiom, who is the officer of Product and Engineering, stated that the term Big Data is referred to the size of dataavailable for analysis and the methods to access and making use of technologies for making sense out of such data.

Big Data encourages a culture of informed decision making where decisions that are data-driven. [1]

Table I. Traditional Data Vs Big Data

\begin{tabular}{|c|c|}
\hline Traditional Data & Big Data \\
\hline Documents & Photos \\
\hline Records & Graphics, Audio and Video \\
\hline Files & GPS data \\
\hline
\end{tabular}

Table II. Small Data Vs Big Data

small data

BIG DATA

gigabytes to terabytes

centralized

\begin{tabular}{|c|c|}
\hline centralized & DISTRIBUTED \\
\hline & SEMI-STRUCTURED AND \\
structured & UNSTRUCTURED \\
\hline
\end{tabular}

stable data model

FLAT̃ SCHEMAS

FEW COMPLEX

known complex interrelationships

(Source: www.wikibon.org)

Big Data is often characterized by Volume, Velocity, Variety, and Veracity. 
According to TechAmerica Foundation's Federal Big Data Commission, 2012, "Big data refers to large volumes of high velocity, complex and variable data that require advanced techniques and technologies to enable the capture, storage, distribution, management, and analysis of the information.”.

Gartner in 2012, updated the definition of big data by adding a few more properties such as High Variability, High complexity, High Value [3].

\section{Big Data Market Growth}

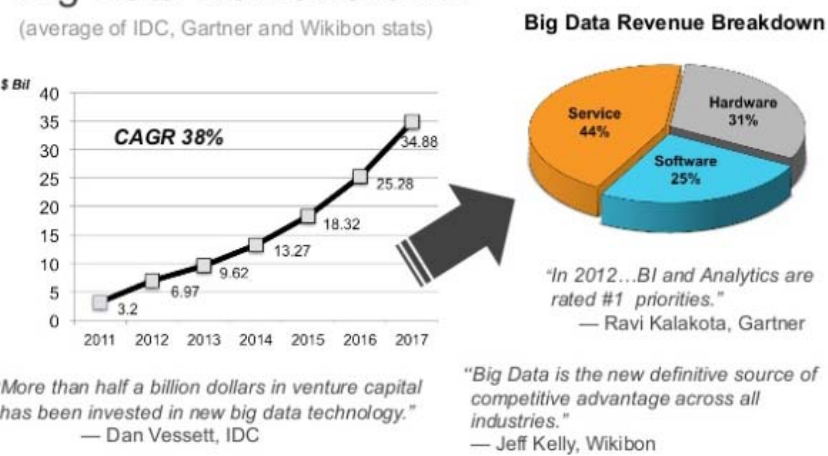

Fig. 2 Market Growth of Big Data

According to IDC, revenues for big data across the world and business analytics will increase to more than \$203 billion by 2020. By 2025, there will be around 180 Zettabytes of data per year.

B. Analytics: Analytics helps to ascertain what has changed and how we should react. Use of advanced analytics helps to discover niche customer segments, categorize the best suppliers, understand sales seasonality, and so forth [4].

3. Big Data Analytics:Big data analytics refers to the application of advanced analytic techniques to larger datasets. Hence, big data analytics is about big data and analytics-plus how the two have turned up to create Business Intelligence (BI) [5].

4. E-Business:E-Business (Electronic Business) is the conducting business on the Internet most often using web technologies. E-Business facilitates companies to collaborate their internal and external processes more efficiently and effectively, and work more closely with suppliers and partners leading to improvements in overall business performance [6].

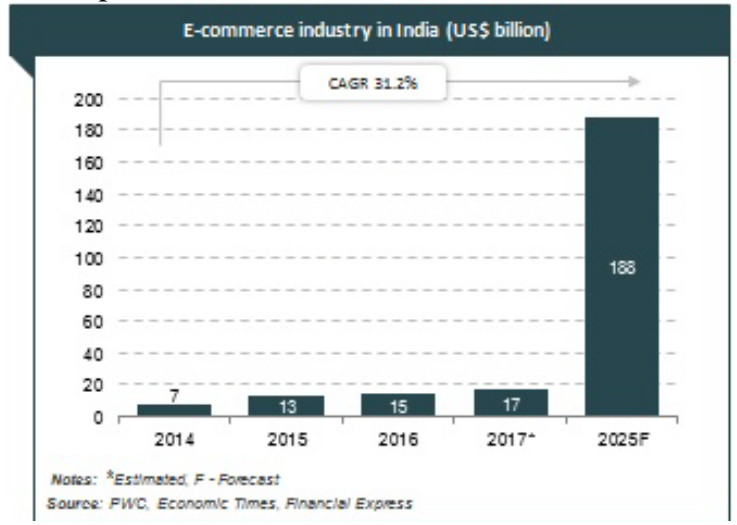

Fig 3. Indian E-commerce Industry (US\$ billion) (Source:www.ibef.org)

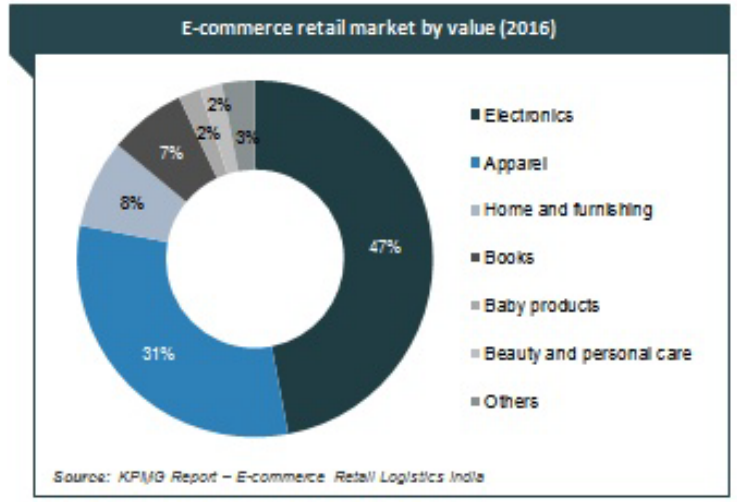

Fig 4. E-Commerce retail by value (2016) (Source:www.ibef.org)

\section{CHARACTERISTICS OF BIG DATA}
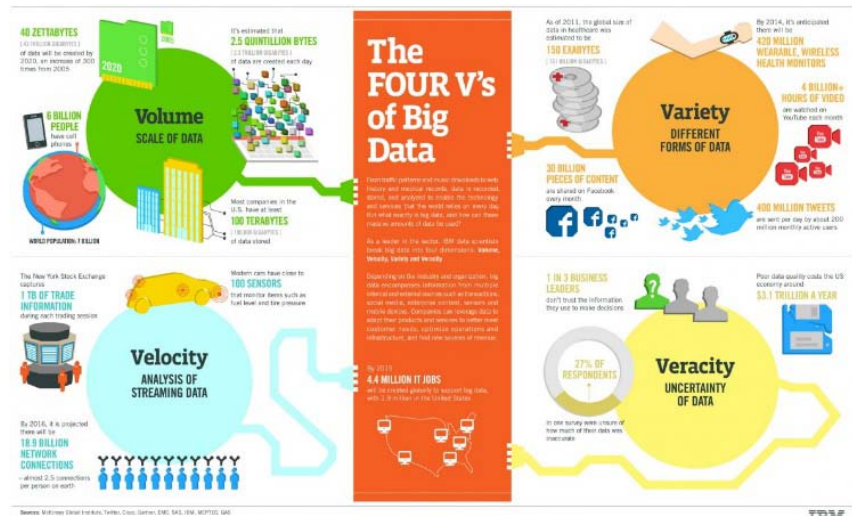

Fig. 5 Four Vs of Big Data

(Source: www.ibmbigdatahub.com)

A. Data Volume. Volume expresses the measures of the amount of data available to an organization. It represents a challenge because in order to manipulate and analyze a big volume of data requires a lot of resources.[4]

B. Data Velocity. Velocity refers to the speed at which the data gets generated, streamlined and arithmetic operations are performed. Data Velocity determines the speed at which data is created, streamlined and aggregated. E-Commerce firms have drastically increased the pace and fertility of data used for business transactions. [7]

C. Data Variety.Variety refers to the different types of data that are generated and that are stored in the database. It is used to measure the relevance of data representation. The data that is generated through E-Commerce business may be in the form of text, audio, video, and images. [8]

D. Data Veracity.Veracity refers to the conformity to truth or factual details. The data that is getting generated can vary largely. The correctness of analysis depends on the veracity of data source. [20]

E. Data Value:The main aim of use of big data is to create business value. Firms should be able to develop meaningful insights that can derive economic value. It measures the usefulness of data in making decisions. [9] 


\section{AIMS OF THE RESEARCH PAPER}

A. To understand the need for Big Data Analytics in E-Business

B. To explore the opportunities for E-Business by use of Big Data Analytics

C. To address the Big Data challenges faced by EBusiness

D. To foresee the trends in future.

\section{A. To understand the need for Big Data Analytics in E-Business}

\section{Big Data Analytics for E-Business.}

"You can't manage what you don't measure." [10]

E-Business companies are gathering more data than they know what to do with and how to deal with it. To turn all this information into a competitive advantage, they'll need new skills and techniques.

Large datasets containing a variety of data types are processed by big data analytics that aims to uncover hidden patterns, unknown correlations, market trends, customer preferences and other useful business information.

Akter, S., and Wamba, S.F, 2016 in their research gave a detailed explanation of the important applications of big data. The main areas of applications included personalization, customer service, predicting customer behavior, dynamic pricing, visibility in supply chain and detecting \& managing fraud. [5]

Data in E-Commerce may be in Structured, SemiStructured and Un-Structure forms and are generated from different sources.

Such sources include:

a. Machine generated data that are generated from real-time sensors

b. Human-generated data that are generated through social media, tweets, photos, videos and status updates.

c. Organization generated data that are of the traditional type comprising information related to business transactions.

The analysis of such data leads to data-driven decision making for implementing effective marketing strategies, opportunities for new revenue generation, improve customer service, better operational efficiency and gain the competitive advantage against competitor organizations. [11]

By use of Big Data Analytics E-Businesses can derive timely insights from the vast amounts of data that are generated from external third-party sources, the Internet, social media and remote sensors.

It is possible to do Real-time monitoring and forecasting of events that impact either business performance or operation. By using Big Data Analytics it is possible to find, acquire, extract, manipulate, analyze, connect and visualize data [12].

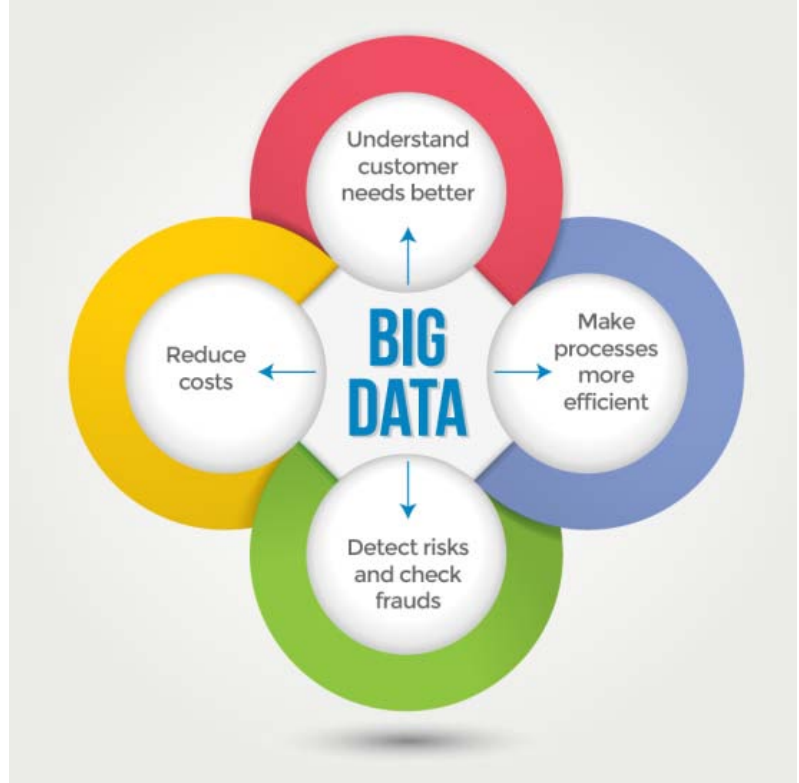

Fig 6. Ways to increase business productivity with Big Data (Source: www.promptcloud.com)

\section{B. To explore the opportunities for e-business by use of big data analytics}

Unlike before where big data used to be a technical problem, now it's a business opportunity. Enterprises today, are exploring big data to discover facts they didn't know before.

Using advanced analytics, businesses can study big data to understand the current state of the business and track stillevolving aspects such as customer behavior. Visualization and advanced analytics are poised for aggressive adoption [12]. Big Data Leads to Insights, Improvements \& Automation [3].

As mentioned in the Gartner Research, Big Data can significantly impact on your business in three different ways that include

a. Discovering the hidden insights from the available data

b. Improvise decision making by enriching information

c. Automating the business processes.

A research firm in association with MIT, in 2012, mentioned that the firms that make use of Big Data Analytics outshined their competitors by $5 \%$ in terms of productivity and $6 \%$ in terms of profitability.

By coupling voluminous information, big data analytics helps organizations to devise consumer-centric insights for improving business operations. [11]

\section{To address the Big Data Challenges faced by $E$ - Business}

1. Challenges faced: Use of Big Data Analytics calls for people with specialized skills, sponsors and robust technologies and architectures.

E-Business houses need to have the ability to ingest data in quick turnaround time given design, cleansing, and distillation required to align to semantics and syntax of enterprise canonical data model. 
To understand that there is a High latency between the time data is generated to the time when data is available for consumption.

Data privacy, security and piracy and legal aspects [13].

Challenges in difficulty in verification of authenticity and precision of data. Complexity in integrating the non-traditional kinds of data with traditional data from other enterprise systems for analysis. [13]

\section{Other challenges include:}

a. Data Acquisition and Recording and Cleaning[23]

b. Data Integration, Aggregation, and Representation

c. Query Processing, Data Modeling, and Analysis[23]

d. Interpretation [14]

e. Complex and Evolving Relationships

f. Data complexity, Computational complexity, System complexity [15]

3. Addressing the challenges: To overcome the challenges, E-Businesses need to adopt big data analytics that is driven by a perfect blend of technologies, management, and economics. Real-time processing of streaming big data is crucial to finding meaningful data and reacting to it. [16]

\section{Big Data Trends to look for in the future.}

1. Big Data to facilitate prescriptive analytics:Prescriptive analytics reduces the risk in tactical decision making to surgeprofitability, enhance customer satisfaction, and create opportunities by leveraging the big data.

2. Focus on Data quality over quantity:Big data, it presents a challenge in combining with the opportunity. The subject under attention is to govern what data to focus on and what to ignore as focus on the wrong datasets wouldn't yield the expected results for the particular business needs.

3. Artificial Intelligence to enhance security and safety of data:Artificial Intelligence (AI) is likely to methodically inspect the security domain. Machines will be able to predict human psychology accurately and comprehend unlabeled data without any human intervention.

4. Specialization of job roles: The massive increase in the value and volume of big data would enable the companies to adopt innovative ways to bring in data scientists and other related experts for specific job roles to handle various stages in the data pipeline such as ETL (extraction, transformation, loading) analytics etc. (Source: www.sssdecisions.com, top 5 Big Data Trends to look for in 2018, Mar 01 2018)

\section{FINDINGS}

Use of big data technology is considered as an opportunity and not a problem. [18]. Bringing in big data for E-Business brings along with it valuable associate called Agility.

Making the best use of big data technologies and harnessing benefits requires trailing and far-reaching search for data.
By using big data analytics technology in e-business brings benefits of having better customer relations, enhanced business performance, better productivity and modern capabilities.[19].

But there is a resilience about profit potential where experts opine that use of big data does not automatically bring profits.[22].

There are several business models depicting interdependent ecosystem of data. Deriving the best out of use of big data means having a clear-cut business model and making its prime importance to the business. [17]

\section{CONCLUSIONS}

Big Data Analytics has gained notable attention due to its ability to transform business practices and the possibility for use of wide range of effective decision-making tools and services [21].

Use of Big Data technologies has made it easier to capture, store and analyze unstructured data in the enterprise. The future looks very promising as it analyzes all kinds of unstructured data, with a goal to make better decision making.[20]

However, there are several challenges that need to be addressed before Big Data technologies will attain its full potential. Using big data empowers decision makers to decide on the basis of evidence rather than intuition. For that reason, it has the potential to revolutionize E-Business.

\section{REFERENCES}

[1] Monica Bulger, Greg Taylor, Ralph Schroeder, Data-Driven Business Models: Challenges and Opportunities of Big Data, Oxford Internet Institute September 2014

[2] Walunj Swapnil K. et.al, Big Data: Characteristics, Challenges and Data Mining, International Journal of Computer Applications (0975 - 8887), ICAIM - 2016

[3] Amir Gandomi, MurtazaHaider, International Journal of Information Management Volume 35, Issue 2, April 2015, Pages $137-144$

[4] Akter, S., \& Wamba, S.F. (2016). Big data analytics in eCommerce: a systematic review and agenda for future research. Electron Markets, 26, 173- 194.

[5] Minelli, M., Chambers, M., \&Dhiraj, A. (2013). Business analytics (pp.99-125). Big Data, Big Analytics: Emerging Business Intelligence and Analytic Trends for Today Businesses.

[6] Kang, K.-D., Son, S. H., \&Stankovic, J. A. (2003). Differentiated real-time data services for E-commerce applications. Electronic Commerce Research, 3, 113-142.

[7] Xindong Wu, , Xingquan Zhu, Gong-Qing Wu, Wei Ding, Data Mining with Big Data, IEEE Transactions On Knowledge And Data Engineering, Vol. 26, No. 1, January 2014

[8] Rishabh Mishra et.al BIG DATA: OPPORTUNITIES AND CHALLENGES, International Journal of Computer Science and Mobile Computing, Vol.4 Issue.6, June- 2015, pg. 27-35

[9] EDPS, Meeting the challenges of big data, 19 November 2015

[10] Tambe, P. (2014). Big Data Investment, Skills, and Firm Value. Management Science, 60(6): 1452-1469.

[11] Beath, C., Becerra-Fernandez, I., Ross, J., \& Short, J. (2012). Finding value in the information explosion. MIT Sloan Management Review, 53, 18-20.

[12] NguyễnThịThúyHoài, College of technology _ Danang University, BIG DATA - OPPORTUNITIES AND CHALLENGES, International Journal of Innovative 
Research in Technology \& Science(IJIRTS), ISSN:23211156

[13] Stephen Kaisler ; Frank Armour ; J. Alberto Espinosa ; William Money. Big Data: Issues and Challenges Moving Forward, 46th Hawaii International Conference on System Sciences (HICSS), 2013, ISSN :1530-1605

[14] ZaharaddeenKaramiLawal et.al, A review: Issues and Challenges in Big Data from Analytic and Storage perspectives, International Journal Of Engineering And Computer Science ISSN:2319-7242 Volume - 5 Issue -03 March, 2016 Page No. 15947-15961

[15] K. S. Dr. Jangala., M. Sravanthi, K. Preethi and M. Anusha, "Recent Issues and Challenges on Big Data in Cloud computing," IJCST , , vol. Vol. 6, no. Issue 2, April - June 2015.

[16] SUBHANKAR DHAR et.al, CHALLENGES AND BEST PRACTICES FOR ENTERPRISE ADOPTION OF BIG DATA TECHNOLOGIES, Journal of Information Technology Management Volume XXV, Number 4, ISSN\#1042-1319, 2014

[17] Christian, B., Boncz, P., Brodie, M.L., and Erling, O. 2011. "The Meaningful Use of Big Data: Four Perspectives - Four Challenges," in Proceedings of the Twenty-five Semantic
Web and Database researchers met at the 2011 STI Semantic Summit, Riga, Latvia.

[18] Philip Russom, BIG DATA ANALYTICS, TDWI BEST PRACTICES

REPORT, FOURTH QUARTER 2011

[19] Liebowitz, J. (2013). Big data and business analytics. Boca Raton: CRC Press.

[20] Avinash B.M. et.al, Big Data Analytics for E-Commerce Its Impact on Value Creation, International Journal of Advanced Research in Computer and Communication Engineering ISO 3297:2007 Certified Vol. 6, Issue 12, December 2017

[21] Wei Fan, Albert Bifet. Mining big data: current status, and forecast to the future, ACM SIGKDD Explorations Newsletter, Volume 14 Issue 2, December 2012

[22] Deepak S. Tamhane, Sultana N. Sayyad. Big Data Analysis Using Hace Theorem, International Journal of Advanced Research in Computer Engineering \& Technology (IJARCET) Volume 4, Issue 1, January 2015

[23] Kale Suvarna Vilas. Big Data Mining. International Journal of Computer Science and Management Research eETECME October 2013, ISSN 2278-733X 